\title{
NEW OPPORTUNITIES OF LOW-COST PHOTOGRAMMETRY FOR CULTURE HERITAGE PRESERVATION
}

\author{
Roman Shults ${ }^{a}$ \\ ${ }^{a}$ Kyiv National University of Construction and Architecture, Faculty for Geoinformation Systems and Territory Management, \\ Povitroflotskyi Avenue, 31 Kyiv, 03037, Ukraine, r-schultz@mail.ru
}

\section{Commission V WG V/7}

KEY WORDS: Low-cost photogrammetry, Camera calibration, Smartphone, Fortification objects, Smartphone measuring tools, Pillbox.

\begin{abstract}
:
In the paper, the questions of using the technologies of low-cost photogrammetry in combination with the additional capabilities of modern smartphones are considered. The research was carried out on the example of documenting the historical construction of the II World War - the Kiev Fortified Region. Brief historical information about the object of research is given. The possibilities of using modern smartphones as measuring instruments are considered. To get high-quality results, the camera of the smartphone was calibrated. The calibration results were used in the future to perform 3D modeling of defense facilities. Photographing of three defense structures in a different state: destroyed, partially destroyed and operating was carried out. Based on the results of photography using code targets, 3D object models were constructed. To verify the accuracy of the 3D modelling, control measurements of the lines between the code targets at the objects were performed. The obtained results are satisfying, and the technology considered in the paper can be recommended for use in performing archaeological and historical studies.
\end{abstract}




\section{INTRODUCTION}

Preservation the historical and cultural heritage is one of the main tasks of any state. In this case to such objects may include various types of structures, are widely known to the public, as well as less known and sometimes abandoned. In the case of the latter, to date it is primarily a task of restoring such objects of cultural heritage. The separate category of cultural heritage objects are the fortification constructions. In the world today, where historic sites are under the influence of various anthropogenic and natural factors, documentation of cultural heritage can help in monitoring tasks, restoration and recovery of such structures (Salvador, et al, 2011, Kapica, et al. 2013, Kersten, et al. 2015, Rodríguez-Gonzálvez, et al. 2015). Conventionally, for such a task the most popular and studied is the technology of close-range or terrestrial photogrammetry. With the advent of digital photography, and multi-function software, almost every user has the possibility to use the technology of terrestrial photogrammetry to solve various practical problems. The most popular among non-professional users of photogrammetric technologies are inexpensive digital cameras, which are equipped with mobile phones, smartphones, tablets etc. Today, almost anyone can in a few minutes, take the pictures of the object, and not knowing the features of images photogrammetric processing in automatic or semi-automatic mode to execute the construction of high-quality threedimensional models. This technology is called low-cost photogrammetry (Gruen, et al. 2008). In the case of solving the problem of cultural heritage objects documentation, this technology is effective in terms of cost and speed of work. However, the qualitative and quantitative assessment of the results still remains one of the most important tasks of professional photogrammetry. In the present work attempt to study the theoretical and practical low-cost photogrammetry technology as an example of documentation the fortifications II World War near the city Kiev was done.

One of the most dramatic stages of the II World War is considered the defence of Kiev, known as The First Battle of Kiev. Defence Kiev lasted for 72 days from July $7^{\text {th }}$ up to September $26^{\text {th }}, 1941$. The most important role in this operation played The Kiev Fortified Region (Russian abbreviation KiUR). Unique defence complex of defensive structures, consisting of permanent and field fortifications and engineering obstacles and long anti-tank ditches. The main parts of Kiev Fortified Region were the battalion defence areas with pillboxes. The building of these objects was started in 1929 and was not finished in 1941. The total length of the fortified region is about $85 \mathrm{~km}$ from the river Dnieper coast on the North from Kiev to the river Dnieper coast on the South from Kiev. Generally, The Kiev Fortified Region had the three fortifications lines with depth from 1 to 6 $\mathrm{km}$. The total amount of different fortifications is up to 600 without additional entrenchments and trenches around each object.

By the Decision of the Cabinet of Ministers of Ukraine in 1993 The Kiev Fortified Region was granted the status of a museum. For more than 20 years, unfortunately, an inventory of the state of The Kiev Fortified Region was not held. Today, thanks to low-cost photogrammetry technology, the opportunity to explore this unique object and create three-dimensional model of the defence area has appeared (Shults, et al. 2017).

The key point of this research was a complex using of smartphone camera images and smartphone's measuring application (Smart Tools). The basic equipment that were used: laser Leica Disto (to perform control measurements); laptop (for calibrating the cameras and three-dimensional modelling); smartphone MEIZU M3 Max (for pictures capturing) and AgiSoft Photoscan (for the three-dimensional modelling).

\section{SMARTPHONE CAMERA CALIBRATION}

Since the main source of data is a digital photo, the quality of the obtained 3D model will depend on the quality of the original photographs. The one way to increase geometric accuracy of photo images is calibration. For calibration, we used flat test objects, which were displayed on laptop screen.

During calibration were determined the next parameters: focal distance, principal point coordinates, coefficients of radial and tangential distortion, affinity coefficient. For non-linear distortions, modelling was used well-known Brown's distortion model. Curves of radial and tangential distortion is presented below.

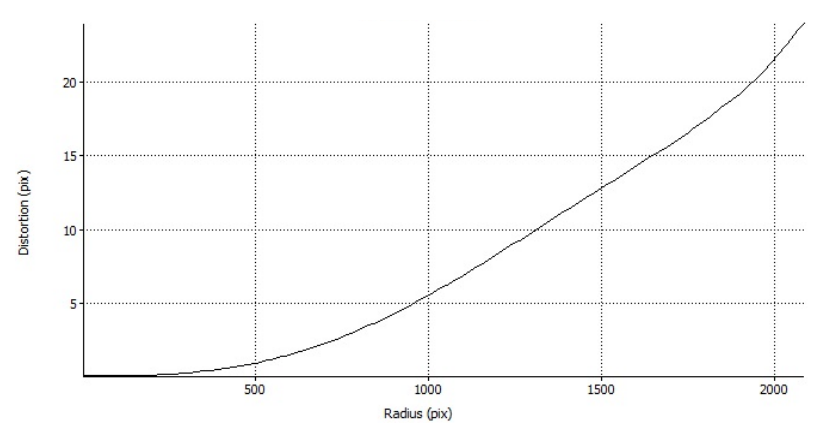

Figure 1. Radial distortion curve

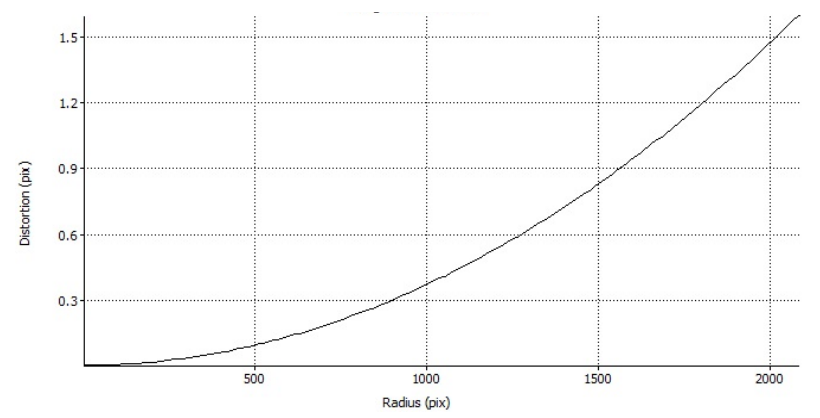


Figure 2. Tangential distortion curve

The parameters of smartphone camera calibration and its errors presented on Figure 3.

\begin{tabular}{lll} 
Image width & 4208 & \\
\hline Image height & 3120 & \\
Focal length & 3130.89 & 0.910058 \\
Principal point $(\mathrm{x})$ & 14.0823 & 0.560249 \\
Principal point $(\mathrm{y})$ & 30.9904 & 0.449205 \\
Affinity B1 & -0.597438 & 0.108471 \\
Skew B2 & 0 & 0 \\
Radial K1 & 0.0723716 & 0.00125557 \\
Radial K2 & -0.207714 & 0.00466298 \\
Radial K3 & 0.232216 & 0.00524349 \\
Radial K4 & 0 & 0 \\
Tangential P1 & 0.00108523 & $6.73613 \mathrm{e}-05$ \\
Tangential P2 & 0.000377202 & $4.73983 \mathrm{e}-05$ \\
Tangential P3 & 0 & 0 \\
Tangential P4 & 0 & 0
\end{tabular}

Figure 3. Calibration results

These results are showing big camera distortion but at the same time, quality of calibration is not bad and all parameters were determined with sufficient accuracy. Therefore, we can try to use this camera for images capturing.

\section{OBJECTS OF RESEARCH}

After a smartphone camera calibration was done a photographing was made. As a test object, we chose two pillboxes № 451, № 428 and artillery observation post № 453 . On this example of the test object, we will try to evaluate the effectiveness of low-cost photogrammetry technology.

The position of objects on fragment of topographic map is presented on Figure 4.

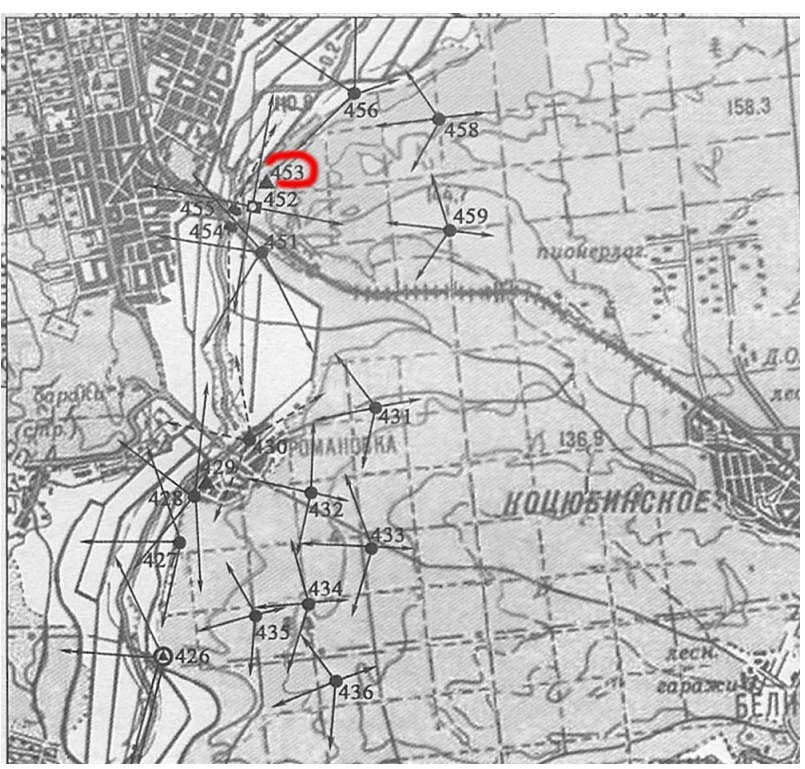

Figure 4. The position of objects on topographical map scale $1: 100000$

The first fortified object is pillbox № 428 (Figure 5 and Figure 6 ). It is a two-storey, machine-gun pillbox with four loopholes.

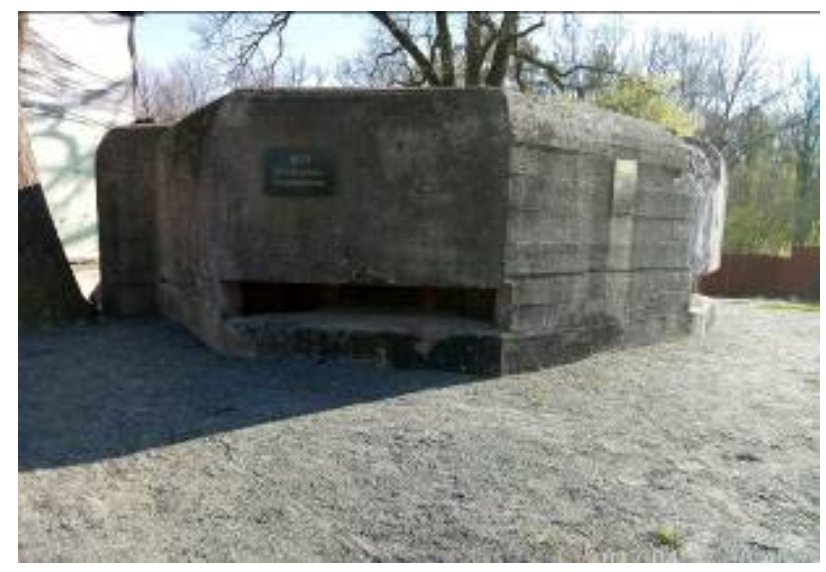

Figure 5. Machine gun pillbox № 428 


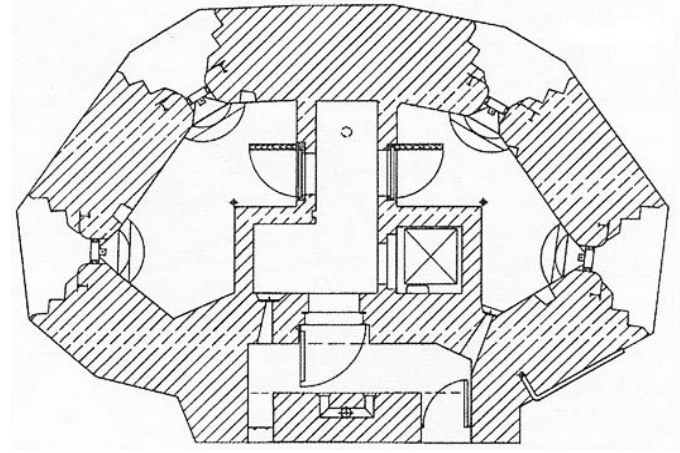

Figure 6. Horizontal cross-section of machine gun pillbox № 428 on upper floor (Kainaran, et al. 2011)

The photographing of this object was made without coded targets, as object has good texture and photographing conditions allow capturing images from any sides. Totally were got 62 images

The second fortified object is pillbox № 451 (Figure 7 and Figure 9). It is a one-storey, machine-gun pillbox with four loopholes.

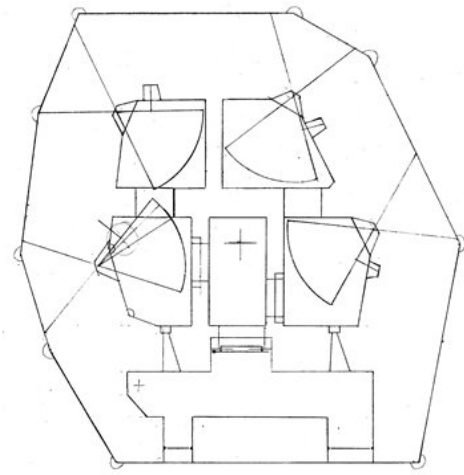

Figure 7. Scheme of pillbox № 451 (Kainaran, et al. 2011)

During the liberation of Kiev in 1943 the object was partially destroyed. The photographing of this object was made with 16 bit coded targets, as object has not so good texture as in the first case and photographing possible only from particular sides due to trenches and trees. Totally were got 45 images.

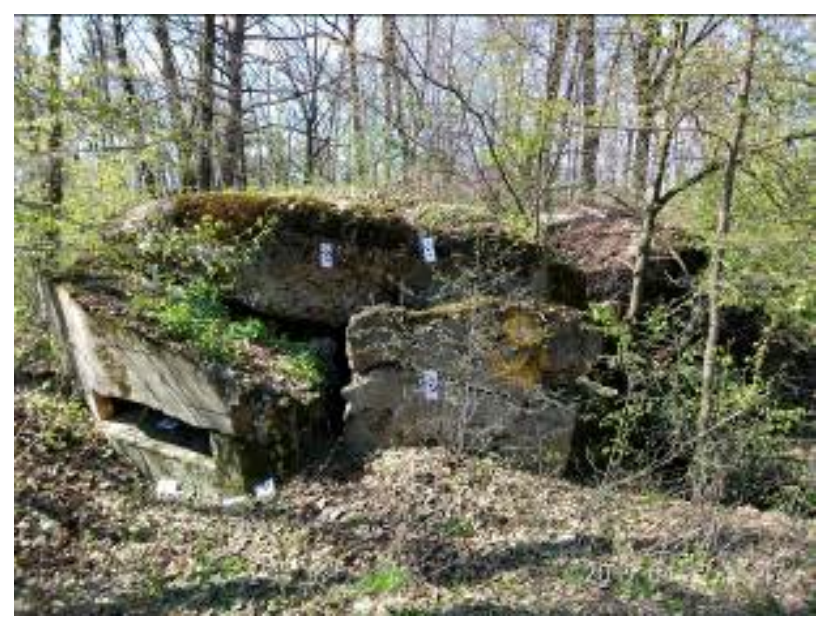

Figure 8. Image of pillbox № 451 with coded targets

The third object is artillery observation post № 453 with armored cover. It is a one-storey object.

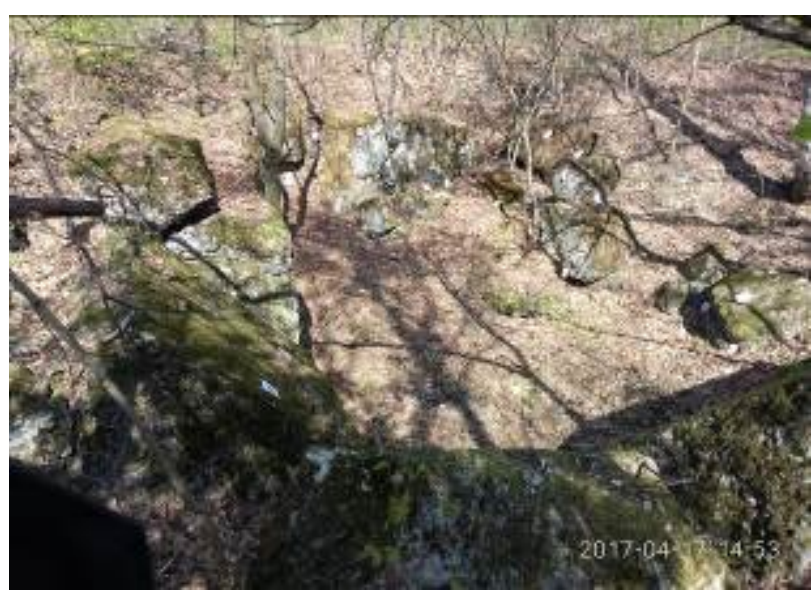

Figure 9. Image of artillery observation post № 453 with coded targets

During the liberation of Kiev in 1943 the object was totally destroyed. The photographing of this object also was made with 16 bit coded targets. Totally were got 94 images.

In all cases, MEIZU M3 Max camera was used. For getting, a metric model has been used information, obtained by the application Android Smart Tools. This application is very useful and allows measuring distances, heights, inclinations and magnetic azimuths using just smartphone without any additional geodetic equipment. 


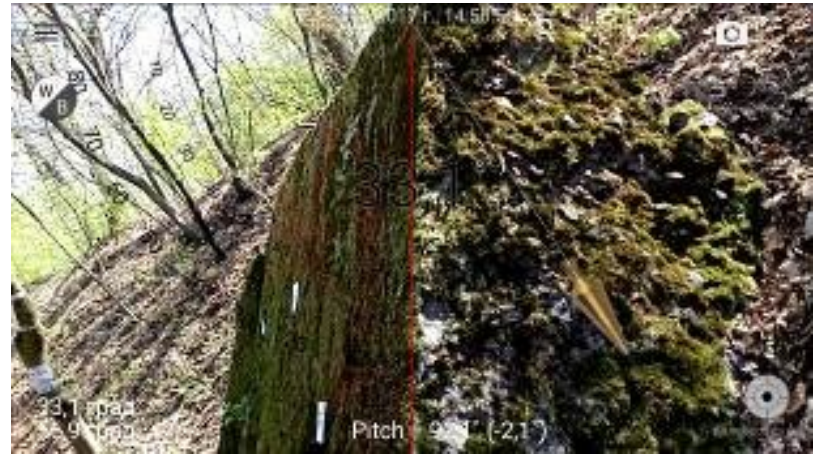

Figure 10. Example of inclination measurement

In our case, we measured just distances and heights in order to scale an object. In addition, we used GNSS coordinates for final 3D model referencing.

\section{3D MODELLING}

The obtained photos and calibration results allow performing a 3D modelling by the photographic images. For 3D modelling, we used software AgiSoft Photoscan, which allows creating 3D models with point cloud in automatic mode (Jiroušek, et al. 2014). Below we are presenting results of $3 \mathrm{D}$ modelling for pillbox № 428

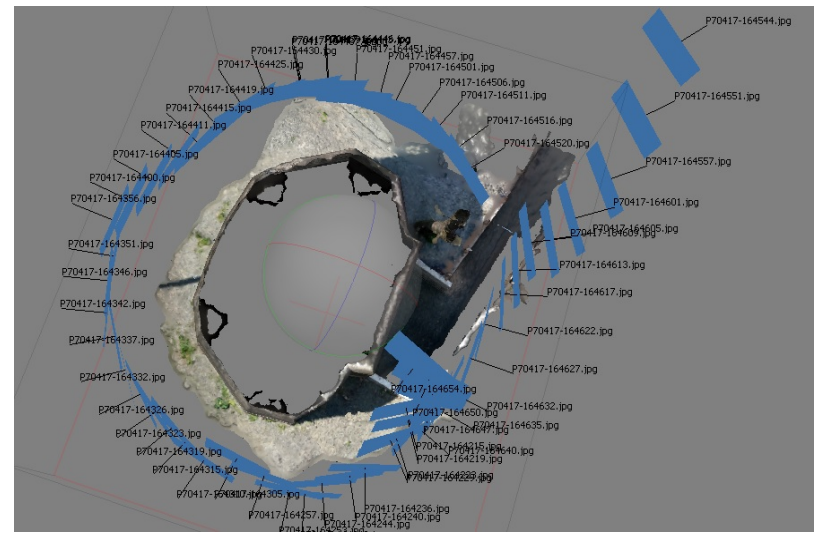

Figure 11. Camera geometry for pillbox № 428

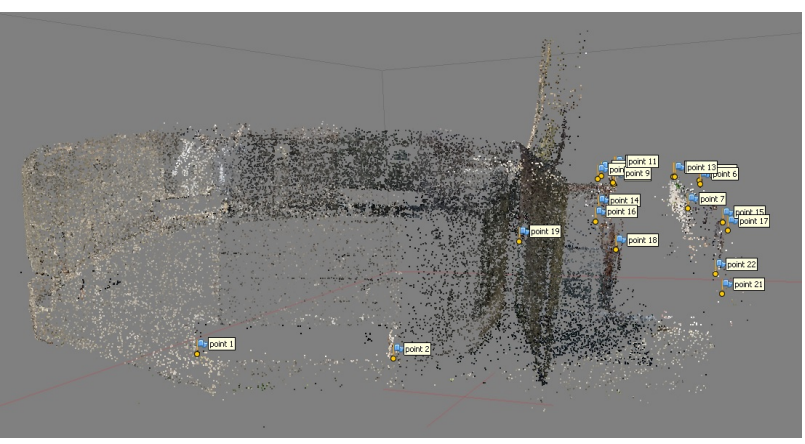

Figure 12. Point cloud of pillbox № 428 with trench

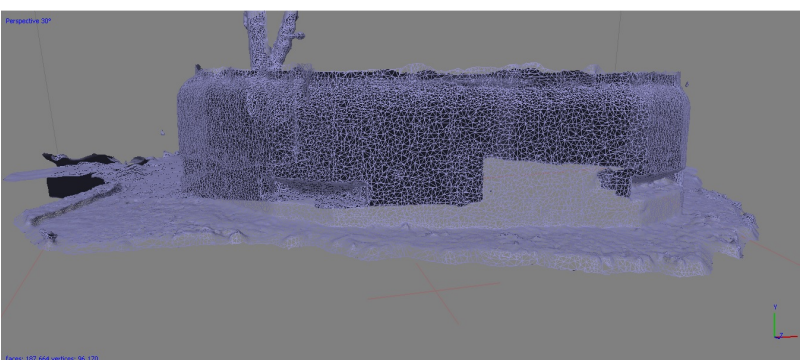

Figure 13. TIN model of pillbox № 428

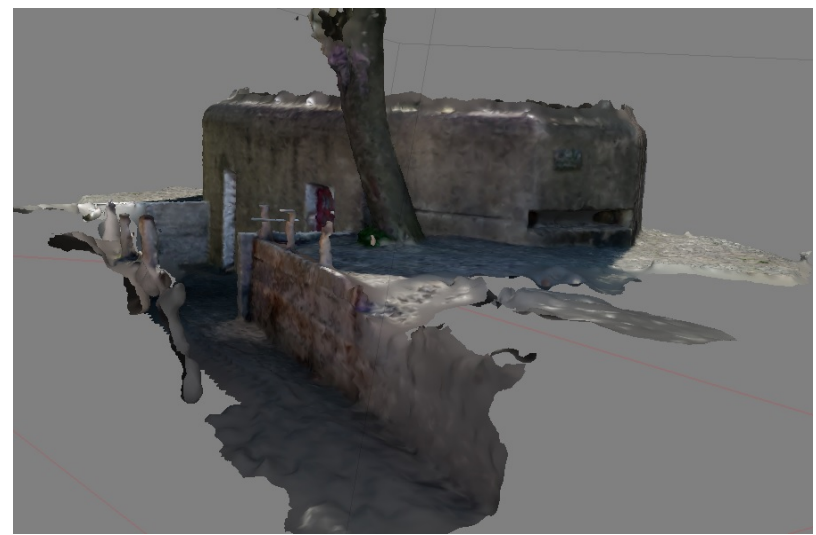

Figure 14. 3D model of pillbox № 428 with trench

In order to check the final model accuracy were made control measurements of distances between the coded targets on the artillery observation post № 453. These distances were measured by Android Smart Tools and Leica Disto. The results are given in Table 1

\begin{tabular}{|c|c|c|}
\hline Line & Distances from Android & Distances from \\
\hline
\end{tabular}




\begin{tabular}{|c|c|c|}
\hline & Smart Tools, $\mathrm{m}$ & Leica Disto, $\mathrm{m}$ \\
\hline $38-39$ & 1.4 & 1.135 \\
\hline $1-2$ & 1.5 & 1.318 \\
\hline $3-1$ & 1.0 & 1.573 \\
\hline $5-7$ & 1.4 & 1.035 \\
\hline $6-5$ & 1.2 & 1.021 \\
\hline $9-10$ & 0.8 & 1.072 \\
\hline $9-12$ & 1.0 & 1.150 \\
\hline $9-11$ & 1.0 & 2.223 \\
\hline $6-12$ & 2.1 & 1.186 \\
\hline $15-13$ & 1.4 & 1.305 \\
\hline $18-15$ & 1.5 & 1.786 \\
\hline $21-19$ & 1.6 & 0.804 \\
\hline $32-33$ & 1.0 & 0.892 \\
\hline $31-32$ & 1.0 & 1.706 \\
\hline $35-35$ & 1.5 & \\
\hline
\end{tabular}

Table 1. Results of control distances measurements

If we accept the Leica Dicto measurement errorless, than we will get root mean square error of Android Smart Tools measurements, which is $0.18 \mathrm{~m}$. This means that resulting model meets the requirements of archaeological and historical measurements.

\section{CONCLUSIONS}

Summarizing the work carried out would like to make the following conclusions. The considered technology of low-cost photogrammetry proved effective enough to meet the challenges for documenting cultural heritage. The resulting accuracy and detail of the models correspond to the requirements for the inventory of the historic structures. During work with inexpensive equipment necessary to provide the mandatory implementation of the photographic equipment calibration twice: directly ahead image capturing and after image capturing. An important element of the technology is to implement control measurements. Because the technology does not provide for the use of surveying equipment (total stations, GNSS precision equipment etc.), the only one option is to carry out control measurements of distances. Such measurements should be at least 5-6 and as much as possible on all sides of object. Modern smartphones allow to measure distances, heights, inclinations of edges and facets, magnetic azimuths. In future, we going to use these measurements as additional constraints in bundle adjustment and research the accuracy of these measurements and them influence on quality of $3 \mathrm{D}$ modelling.

\section{REFERENCES}

Gruen A., Akca, D. 2008. Metric accuracy testing with mobile phone cameras, ISPRS Archives XXIst ISPRS Congress Technical Commission V., Volume XXXVII Part B5, China, pp. 729-736.

Jiroušek, T., Kapica, R., Vrublová, D. 2014. The testing of Photoscan 3D object modelling software, Geodesy and Cartography, Volume 40, Issue 2: pp. 68-74. http://dx.doi.org/10.3846/20296991.2014.930251 .

Kainaran, A.V., Kreshchanov, A.L., Kuzyak, A.G., Yushchenko, M.V., 2011. Kiev fortified region: 1928 - 1941: (History, Prewar service, Today's day). Volyn. 356 p.

Kapica, R., Vrublová, D., Michalusová, M., 2013. Photogrammetric documentation of Czechoslovak border fortifications at Hlučín-Darkovičky, Geodesy and Cartography, $\begin{array}{lllll}\text { Volume } 39, \quad \text { Issue } & \text { 2: } & \text { pp. }\end{array}$ http://dx.doi.org/10.3846/20296991.2013.806243.

Kersten, T., Lindstaedt, M., Maziull, L., Schreyer, K., Tschirschwitz, F., Holm, K. 2015. 3D recording, modelling and visualisation of the fortification Kristiansten in Trondheim (Norway) by photogrammetric methods and terrestrial laser scanning in the framework of Erasmus programmes, In: The International Archives of the Photogrammetry, Remote Sensing and Spatial Information Sciences, XL-5/W4, pp. 55-262. doi:10.5194/isprsarchives-XL-5-W4-255-2015.

Rodríguez-Gonzálvez, P., Nocerino, E., Menna, F., Minto, S., Remondino, F. 2015. 3D surveying \& modeling of underground passages in WWI fortifications In: The International Archives of the Photogrammetry, Remote Sensing and Spatial Information Sciences, XL-5/W4, pp. 17-24. doi:10.5194/isprsarchives-XL-5-W4-17-2015.

Salvador, I., Vitti, A. 2011. Survey, representation and analysis of a War I complex system of surface and underground fortifications in the Gresta Valley, Italy, In: The International Archives of the Photogrammetry, Remote Sensing and Spatial Information Sciences, XXXVIII-5/W16, pp. 319-325. doi:10.5194/isprsarchives-XXXVIII-5-W16-319-2011.

Shults, R., Krelshtein, P., Kravchenko, I., Rogoza, O., Kyselov, O., 2017. Low-cost photogrammetry for culture heritage. Environmental Engineering 10th International Conference, Lithuania, Vilnius, http://doi.org/10.3846/enviro.2017.XXX 